\title{
The influence of simultaneous action of the aggressive environment and loading on strength of RC beams
}

\author{
Jacek Selejdak ${ }^{1}$, Roman Khmil ${ }^{2, *}$, and Zinoviy Blikharskyy ${ }^{1}$ \\ ${ }^{1}$ Czestochowa University of Technology, The Faculty of Civil Engineering, Department of Concrete \\ Structures and Geotechnics, Akademicka 3, 42200 Czestochowa, Poland \\ ${ }^{2}$ Lviv Polytechnic National University, Department of Building Constructions and Bridges, \\ Karpinskogo Str. 6, Lviv, 79013, Ukraine
}

\begin{abstract}
The article is devoted to an experimental research of the strength of reinforced concrete beams, and its dependence on a simultaneous influence of a corrosion environment and a loading factor. The tests have been carried out upon reinforced concrete specimens of $2100 \times 200 \times 100 \mathrm{~mm}$ size, with a regular reinforcement. The beams are of a span equaling to $1,9 \mathrm{~m}$ with different reinforcing ratio of beams. The acid environment, namely $10 \% \mathrm{H}_{2} \mathrm{SO}_{4}$, was taken as a model of an aggressive environment. Reinforced concrete beams have been tested with and without the co-action of the aggressive environment and loading factor. Beams, which underwent a simultaneous action of the corrosive environment and loading, were loaded to a level 0.7 of its load-carrying capacity. The load-carrying capacity in aggressive environment in all the beams of all the series was achieved in 46-60 days. The influence of the simultaneous action of the aggressive environment and loading on the strength of reinforced-concrete beams has been described in the following work. It is necessary to note that the design code of Ukraine does not allow determining load carrying capacity of the beams affected by corrosion with simultaneous influence of loading with adequate accuracy. The analysis of experimental data has been done and the main directions of the design code's correction have been formulated.
\end{abstract}

\section{Introduction}

It is known that reinforced concrete is one of the most widespread building materials. This material has found its application in production and in a constructional engineering [1, 2, $3]$. Its carrying functions are successfully applied in structural designs under a wide range of power load and other influencing factors in different environments. It is known that all existing constructions are influenced in a variety of ways by corrosion processes. Around 20 to $70 \%$ of constructions in nonferrous metallurgy, chemical, wood-pulp and paper industry, and energy-generating factories is affected by various corrosive environments. A corrosion process can last longer when in an aggressive environment of small

*Corresponding author: roman_hl@ukr.net 
concentration whilst, when there is a high concentration corrosive environment, a construction can collapse very quickly.

Durability and load-carrying capacity generally depends not only on loading but also on the influence of the environment [4-7]. Every year losses resulting from corrosion are estimated by different specialists in boundary values of 4-6\% of gross domestic product (GDP) [4]. Constructions of buildings of galvanic workshops, chemical enterprises and other elements of buildings which have a direct contact with reactive material undergo a corrosive processes to the greatest extent $[4,5]$. The outcomes of this process can be the decrease of a cross section of elements, decrease of crack resistance and strength, build-up of deformations.

When constructions which are affected by corrosive environment are exploited, the effect of this interaction should be taken into consideration on the stage of design as well as controlled by specialists. An estimation of the load-carrying capacity of reinforced concrete constructions which have corrosion - mechanical injuries of concrete can be given on the basis of results of theoretical and experimental research.

\section{Experimental research and discussion}

For the experimental research there were made three series of reinforced concrete beams by the sizes of $2100 \times 200 \times 100 \mathrm{~mm}$ with reinforcement in the stretched working area $2 \varnothing 12,14$ and 16 bars $\mathrm{A} 400 \mathrm{C}$ accordingly, and in upper compressed area $2 \varnothing 5 \mathrm{Bp}-1$. The transverse reinforcement was from $\varnothing 5$ bars Bp-1 with step of 75-100 $\mathrm{mm}$. The concrete mix of series is accepted with stone aggregate $10-20 \mathrm{~mm}$. The concrete compressed strength made $44 \mathrm{MPa}$. In general 12 beams (four specimens in each series) were tested.

Firstly, in order to define strength characteristics of experimental beams without the effect of the corrosive environment, they were tested in terms of bending by means of a short term load applied till they fail. The beams were marked BO. Applying of a short term load was achieved with two concentrated forces in one-third of their span. The loads were applied in steps. Thus, deflection, presence and evolution of cracks, deformations of concrete and the reinforcement were fixed. Ultimate limit state (ULS) of beams passed due to the reinforcement's yield in the stretched area of the greatest bending moment with the following failure by crushing of the compressed zone of concrete.

For the research of effect of simultaneous acting of the corrosive environment and load on strength, two beams of each series was investigated, while one of the beams of each series were subjected only by corrosive environment. The beams were marked BD. Schemes of special equipment on which the experimental research was carried out presented on Fig. 1. The testing time of the corresponding beams - twins in the corrosive environment under loading and without loading was accepted as equal. After the beams stayed in the corrosive environment, they were tested in terms of a short term loading till their failure.

Beams undergoing a simultaneous action of the corrosive environment and loading were loaded to a level $70 \%$ from load-carrying capacity of ULS of beam marked BO. The loading's value was controlled by special ring-balance dynamometers. The loading was put with special spring devices which provided a static loading (Fig. 1b). As corrosive environment of $10 \%$ solution of sulphuric acid $\mathrm{H}_{2} \mathrm{SO}_{4}$ was used. Such environments occur in separate chemical productions, electroplating shops, smoke pipes etc. High concentration of solution also resolved for rather small period simulation effect of simultaneous acting of the corrosive environment and loading. 
a)

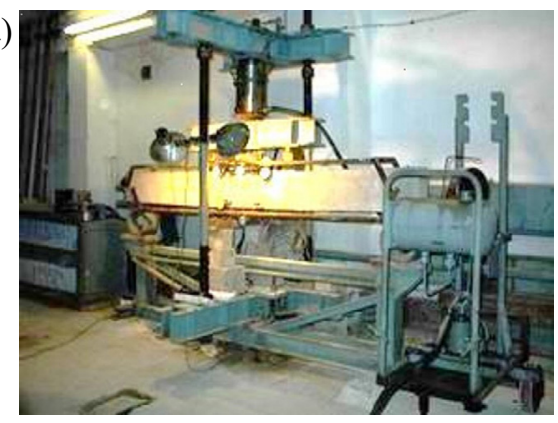

b)

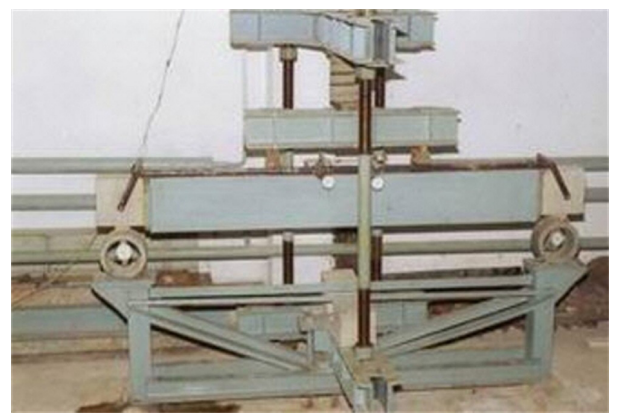

c)

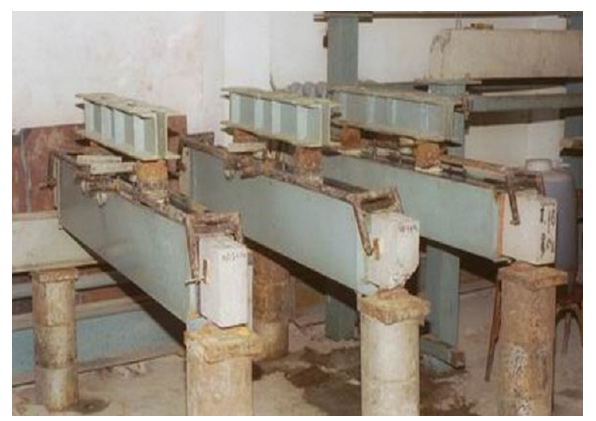

Fig. 1. The experimental specimens during testing: a) on short-term acting of loading; b) on long-term acting of loading and corrosive environments; c) on separate acting of a corrosive environment and loading after one.

The solution of acid was put into special baths, processed with corrosion-resistant coatings, timbered on the beams. The constant supervisory control of concentration of the corrosive environment was carried out. At decrease of concentration of acid more than $1 \%$, according to standards [8], the solution was renewed. During the research, the reinforcement ratio of all beams was changed. It occurred because of corrosion cross section of the concrete. The reinforcement at given loadings level did not corrode. The corrosion of the reinforcing bars was avoided in order to exclude its impact on the stressstrain state of the beams. This effect is more complex and requires a separate study $[5,9]$. At achievement by experimental samples of ULS the reinforcing ratio made for a series 3 (2Ø12) - 1.93-1.99\%, for a series 1 (2Ø14) - 2.6-2.8\%, for a series $4(2 \varnothing 16)-3.43-3.54 \%$.

Achievement of the reinforcement yield of beams of all series was comprised almost equally - for 46-60 days (Table 1).

The final cross section of the concrete of beams at failure after simultaneous acting of the corrosive environment and loading and a beam without acting of loading were approximately equal (Table 1). It does not enable to compare strength of beams at achievement of ULS by them; nevertheless, the comparison of strength at failure of beams was possible (Table 2).

Experimental values of the bending moments which related to load-carrying capacity by ULS and physical failure and also their correlation are presented in Table 2. The theoretical bending moments according to design codes $[10,11,12]$ are also presented in Table 2 . It is necessary to note that the technique of standards [11] allows determining load-carrying capacity of the beams tested without of simultaneous effect of the corrosive environment and loading with adequate accuracy. The deviation between theoretical and experimental values is $1.1 \%$ for a beam of the BD- $4.4 \mathrm{c}$ of a series of 4 and $-0.7 \%$ for a beam of the BD-1.4c of a series 1 towards excess of experimental value above theoretical. 
Table 1. Overall parameters of experimental research.

\begin{tabular}{|c|c|c|c|c|c|c|c|}
\hline \multirow{3}{*}{ 苍 } & \multirow{3}{*}{ Specimens } & \multicolumn{3}{|c|}{ Concrete cross section, $\mathbf{b} \times \mathbf{h}, \mathbf{m m}$} & \multicolumn{2}{|c|}{ Testing time, days } & \multirow{3}{*}{$\begin{array}{c}\text { Type of } \\
\text { destruction }\end{array}$} \\
\hline & & \multirow[b]{2}{*}{$\begin{array}{c}\text { before } \\
\text { influence }\end{array}$} & \multicolumn{2}{|c|}{ during influence } & \multirow{2}{*}{$\begin{array}{c}\text { when } \\
\text { reinforce- } \\
\text { ment yield }\end{array}$} & \multirow[b]{2}{*}{$\begin{array}{l}\text { when } \\
\text { failure }\end{array}$} & \\
\hline & & & $\begin{array}{l}\text { at reinforce- } \\
\text { ment yield }\end{array}$ & at failure & & & \\
\hline \multirow{4}{*}{1} & BO 1.1 & $101 \times 202$ & \multicolumn{2}{|c|}{ without corrosive influence } & \multicolumn{2}{|c|}{ short-time act of loading } & bending \\
\hline & BD $1.2-0.7 \mathrm{c}$ & $99 \times 200$ & $74.4 \times 174.3$ & $65.0 \times 166.0$ & 46 & 56 & bending \\
\hline & BD $1.3-0.7 \mathrm{c}$ & $102 \times 200$ & $70.2 \times 169.6$ & $61.0 \times 166.0$ & 49 & 60 & shear \\
\hline & BD $-1.4 \mathrm{c}$ & $100 \times 206$ & $60.0 \times$ & 67.0 & $\begin{array}{l}\text { short-time a } \\
\text { in } 60 \text { days af }\end{array}$ & $\begin{array}{l}\text { of loading } \\
\text { corrosion }\end{array}$ & bending \\
\hline \multirow{4}{*}{3} & BO 3.1 & $99 \times 208$ & \multicolumn{2}{|c|}{ without corrosive influence } & \multicolumn{2}{|c|}{ short-time act of loading } & bending \\
\hline & BD 3.2-0.7c & $101 \times 208$ & $70.4 \times 177,2$ & $60.0 \times 176.0$ & 46 & 54 & shear \\
\hline & BD 3.3-0.7c & $100 \times 207$ & $68.2 \times 176,9$ & $58.0 \times 174.0$ & 47 & 56 & bending \\
\hline & $\mathrm{BD}-3.4 \mathrm{c}$ & $98 \times 204$ & $60.0 \times$ & 69.0 & $\begin{array}{l}\text { short-time a } \\
\text { in } 56 \text { days af }\end{array}$ & $\begin{array}{l}\text { of loading } \\
\text { corrosion }\end{array}$ & shear \\
\hline \multirow{4}{*}{4} & BO 4.1 & $100 \times 202$ & \multicolumn{2}{|c|}{ without corrosive influence } & \multicolumn{2}{|c|}{ short-time act of loading } & bending \\
\hline & BD $4.2-0.7 \mathrm{c}$ & $102 \times 200$ & $71.3 \times 171,0$ & $66.5 \times 172$ & 50 & 54 & bending \\
\hline & BD $4.3-0.7 \mathrm{c}$ & $99 \times 201$ & $72.9 \times 175.0$ & $65.0 \times 173.0$ & 48 & 57 & bending \\
\hline & BD $-4.4 c$ & $99 \times 202$ & \multicolumn{2}{|c|}{$60.0 \times 171.0$} & \multicolumn{2}{|c|}{$\begin{array}{l}\text { short-time act of loading } \\
\text { in } 57 \text { days after corrosion }\end{array}$} & bending \\
\hline
\end{tabular}

Table 2. Strength of experimental specimens.

\begin{tabular}{|c|c|c|c|c|c|}
\hline \multirow{2}{*}{ 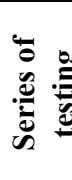 } & \multirow[b]{2}{*}{ Specimens } & \multicolumn{2}{|c|}{$\begin{array}{c}\text { Experimental bending moments, } \\
\mathrm{kN} \times \mathbf{c m}\end{array}$} & \multirow{2}{*}{$\begin{array}{c}\begin{array}{c}\text { Theoretical bending } \\
\text { moments, } \mathbf{k N} \times \mathbf{c m}\end{array} \\
\text { at reinforcement yield } \\
\mathrm{M}_{\mathrm{u}}^{\mathrm{norm}}\end{array}$} & \multirow{2}{*}{$\begin{array}{c}\text { Correlation, } \\
\frac{\mathrm{M}_{\mathrm{u}}^{\text {norm }}}{\mathrm{M}_{\mathrm{u}}^{\exp }}\end{array}$} \\
\hline & & $\begin{array}{l}\text { at reinforcement yield } \\
\qquad \mathrm{M}_{\mathrm{u}}^{\exp }\end{array}$ & $\begin{array}{l}\text { at failure } \\
\mathrm{M}_{\mathrm{f}}^{\exp }\end{array}$ & & \\
\hline \multirow{4}{*}{1} & BO 1.1 & 2539.7 & 2924.7 & 2253.2 & 0.887 \\
\hline & BD $1.2-0.7 \mathrm{c}$ & \multicolumn{2}{|l|}{1759.4} & 1956.9 & 1.112 \\
\hline & BD 1.3-0.7c & \multicolumn{2}{|l|}{1759.4} & 1921.2 & 1,092 \\
\hline & $\mathrm{BD}-1.4 \mathrm{c}$ & 1773.3 & 1959.5 & 1785.6 & 1.007 \\
\hline \multirow{4}{*}{3} & BO 3.1 & 1931.7 & 2084.9 & 1768.6 & 0.916 \\
\hline & BD 3.2-0.7c & \multicolumn{2}{|l|}{1369.9} & 1558.1 & 1.137 \\
\hline & BD 3.3-0.7c & \multicolumn{2}{|l|}{1369.9} & 1550.6 & 1.132 \\
\hline & BD -3.4c & - & 1318.0 & 1467.8 & - \\
\hline \multirow{4}{*}{4} & BO 4.1 & 3166.7 & 36600 & 2809.1 & 0.887 \\
\hline & BD 4.2-0.7c & \multicolumn{2}{|l|}{2141.9} & 2176.9 & 1.016 \\
\hline & BD 4.3-0.7c & \multicolumn{2}{|l|}{2141.9} & 2246.3 & 1.049 \\
\hline & BD -4.4c & 1933.3 & 2122.0 & 1910.5 & 0.989 \\
\hline
\end{tabular}

The analysis of results shows, that simultaneous acting of the corrosive environment and loading for research of load-carrying capacity of beams is a worse possible combination. For beam which was only in the corrosive environment (BD-1.4c) the bending moment at failure was greater $(1959.5 \mathrm{kN} \times \mathrm{cm})$ than for beams (BD 1.2-0.7c; BD $1.3-0.7 \mathrm{c})$ tested under simultaneous acting of corrosive environment and loading $(1759.4 \mathrm{kN} \times \mathrm{cm})$. For beam BD $-4.4 \mathrm{c}$ the bending moment at failure was approximately equal $(2122.0 \mathrm{kN} \times \mathrm{cm}$ ) for beams (BD 4.2-0.7c; BD 4.3-0.7c) tested under simultaneous acting of corrosive environment and loading $(2141.9 \mathrm{kN} \times \mathrm{cm})$. Physical failure of a beam BD-3,4c passed from shear and earlier from load-carrying capacity by ULS. It happened at $1318 \mathrm{kN} \times \mathrm{cm}$ when the theoretical ULS are $1467.8 \mathrm{kN} \times \mathrm{cm}$. The reason of failure was full corrosion of transvers bars for this beam that was not anticipated. 
In general, the results of the beams tested under simultaneous acting of the corrosive environment and loading was worse. It is explained by the fact that the cracks revealed by the microscope in concrete at long acting of loading, being passed round come together at a macro crack. It increases deformability concrete, influences its strength and results in its premature failure. At short-term acting of loading this effect has no time to reveal itself.

The scheme of failure types of beams samples is presented in Fig. 2.

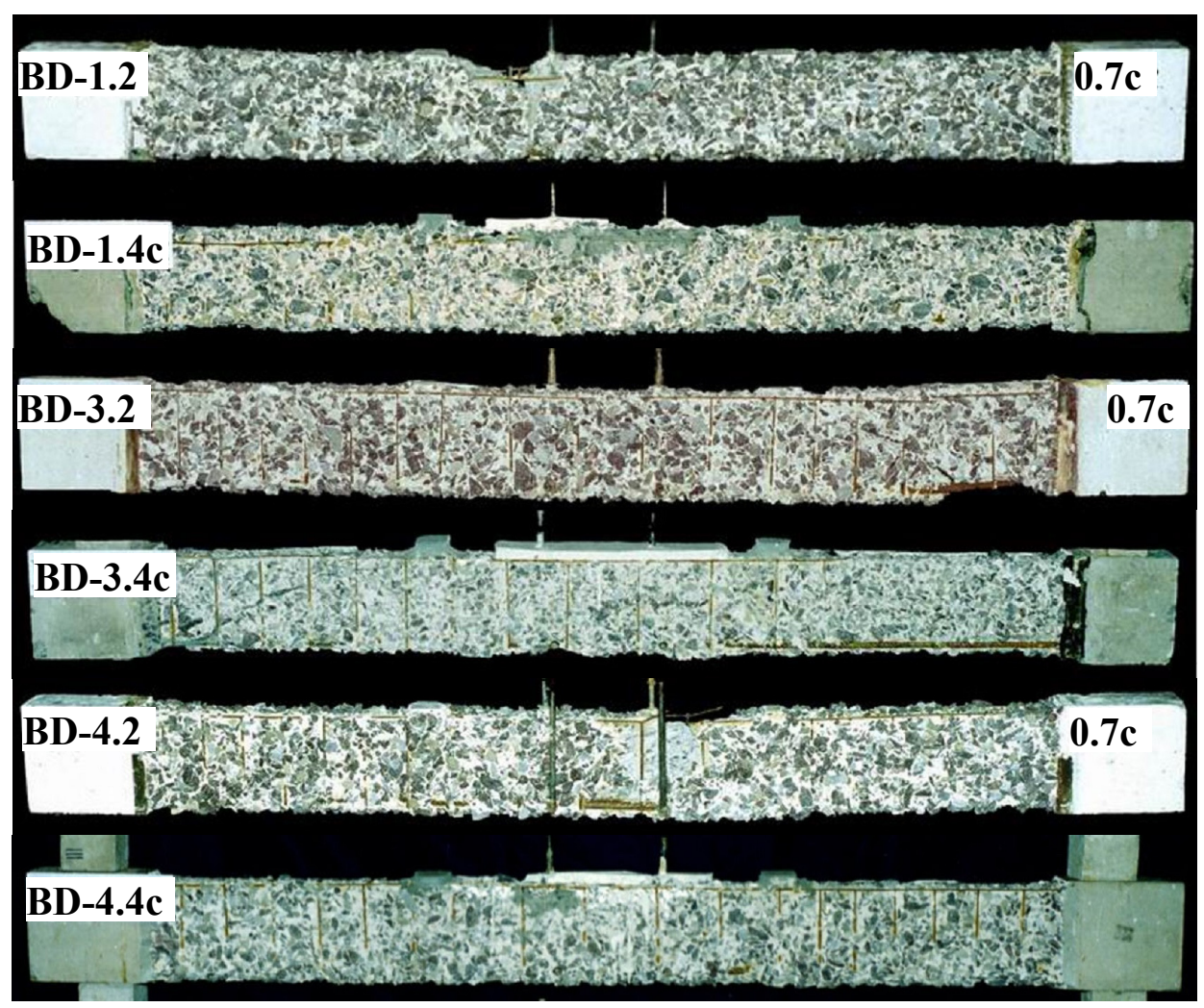

Fig 2. The scheme of typical failure of experimental beams.

This research shows that failure of reinforced concrete beams in environment of sulphuric acid has passed owing to corrosion of concrete, sometimes together with corrosion of the reinforcement. Corrosion of concrete was caused by chemical reactions of acid with constituent parts of cement stone which contains calcium. Thus, corrosion proceeded gradually from external sides of concrete in depth of experimental samples with formation of a contact layer on a surface of concrete. It is necessary to notice; that corrosion of concrete of beams occurred continually from the moment of putting beams into aggressive environment. The quartz sand and granite crushed stone practically did not give in to corrosion, and fell out from the surface of a beam during the corrosion of a cement stone.

The corrosion processes resulted in the decrease of the size of cross section beams over time on linear dependences. The reduction of the area of the compressed zone of concrete, as well as effective height of section, resulted in the increase of stresses in concrete and in the reinforcement. Failure of beams happened with the achievement of stress in the reinforcement of yield line with a further destruction of the compressed zone of concrete. Due to progressive corrosion of practically all of transverse bars, the beam failures caused by shear were appeared. 
The analysis has also shown- that the technique of standards [11] in all cases of the design of bending reinforced-concrete elements with the corrosion damage taking at long simultaneous acting of a corrosive environment and loading does not allow to determine a load-carrying capacity of such elements with the real accuracy. The deviation between theoretical and experimental values increased to $13.7 \%$ towards the excess of theoretical values above experimental. It is explained by the effect of the corrosion micro cracks; as stress concentrators in the compressed concrete and as consequence the decrease of strength of concrete at presence of the corrosion processes and long acting of loading. It is necessary to take into account the presence of a contact concrete layer with the lowest physicalmechanical characteristics and strength. In the control process, testing beams and beams affected by the corrosive environment without simultaneous acting of loading, the technique of standards [11] give sufficient convergence of results. Therefore, the research shows that presence of simultaneous act of corrosive environment and loading significantly influences load carrying capacity of beams.

\section{Conclusions}

1. The analysis of results shows, that simultaneous acting of the corrosive environment and loading for research of load-carrying capacity of beams is a worse combination.

2. The deviation between theoretical and experimental values made up to $13.7 \%$ towards excess of theoretical above experimental ones for beams tested with simultaneous acting of the corrosive environment and loading. At the same time for beams without simultaneous acting the deviation made $-0.7-1.1 \%$.

3. These obtained features should be taken into account when beams applied to real operating conditions are designed.

\section{References}

1. K. Brózda, J. Selejdak, P. Koteš, Procedia Engineering, 192, 64 (2016)

2. M. Mazur, Prod. Eng. Arch., 13(4), 41 (2016)

3. M.A. Fernandez-Ruiz, L.M. Gil-Martin, E. Hernandez-Montes, Int. J. of Concr. Struct. and Mat., 12, 6 (2017)

4. S.N. Alekseev, F.M. Ivanov, S. Modry, P. Shysel, Durability of reinforced concrete in corrosive environment $(316,1990)$

5. D.B. McDonald. D.W. Pfeifer. M. R. Sherman. Corrosion evaluation of epoxy-coated, metallic-clad and solid metallic reinforcing bars in concrete $(124,1998)$.

6. J. Selejdak, R. Ulewicz, M. Ingaldi, 23rd Int. Conf. on Metal.\&Mat. (1882-1888, 2014)

7. G.M. Kotsovou, D.M. Cotsovos, Eng. Struct., 160, 44 (2018)

8. National Standard of USSR, The methods of corrosion tests. General demands (GOST 9.905-82, 5, 1983)

9. C.G Berrocal, I. Lofgren, K. Lundgren, Eng. Struct., 163, 409 (2017)

10. Eurocode 2: Design of concrete structures - Part 1-1: General rules for buildings (EN 1992-1-1:2004 (E), 225, 2004)

11. National Norms of Ukraine, Concrete and reinforced concrete structures (DBN B.2.6 98: 2009, 84, 2011)

12. National Standards of Ukraine, Concrete and reinforced concrete structures with heavy concrete (DSTU B.2.6 - 156:2010, 118, 2011). 